Louisiana State University

LSU Digital Commons

$7-1-2020$

\title{
Dynamic glucose disposal is driven by reduced endogenous glucose production in response to voluntary wheel running: $A$ stable isotope approach
}

Timothy D. Allerton

Pennington Biomedical Research Center

Greg M. Kowalski

The Institute for Physical Activity and Nutrition

Hardy Hang

Pennington Biomedical Research Center

Jacqueline Stephens

Pennington Biomedical Research Center

Follow this and additional works at: https://digitalcommons.Isu.edu/biosci_pubs

\section{Recommended Citation}

Allerton, T., Kowalski, G., Hang, H., \& Stephens, J. (2020). Dynamic glucose disposal is driven by reduced endogenous glucose production in response to voluntary wheel running: A stable isotope approach. American Journal of Physiology - Endocrinology and Metabolism, 319 (1), E2-E10. https://doi.org/ 10.1152/ajpendo.00450.2019

This Article is brought to you for free and open access by the Department of Biological Sciences at LSU Digital Commons. It has been accepted for inclusion in Faculty Publications by an authorized administrator of LSU Digital Commons. For more information, please contact ir@lsu.edu. 


\title{
RESEARCH ARTICLE
}

\section{Dynamic glucose disposal is driven by reduced endogenous glucose production in response to voluntary wheel running: a stable isotope approach}

\author{
Timothy D. Allerton, ${ }^{\mathbf{1}}$ Greg M. Kowalski, ${ }^{2}$ Hardy Hang, ${ }^{1}$ and Jacqueline Stephens ${ }^{1}$ \\ ${ }^{1}$ Pennington Biomedical Research Center, Baton Rouge, Louisiana; and ${ }^{2}$ Institute for Physical Activity and Nutrition, School \\ of Exercise and Nutrition Sciences, Deakin University, Geelong, Australia
}

Submitted 15 October 2019; accepted in final form 23 April 2020

\begin{abstract}
Allerton TD, Kowalski GM, Hang H, Stephens J. Dynamic glucose disposal is driven by reduced endogenous glucose production in response to voluntary wheel running: a stable isotope approach. Am J Physiol Endocrinol Metab 319: E2-E10, 2020. First published April 28, 2020; doi:10.1152/ajpendo.00450.2019.- - To resolve both the systems level and molecular mechanisms responsible for exerciseinduced improvements in glucose tolerance, we sought to test the effect of voluntary wheel running exercise on postprandial glucose dynamics. We utilized a stable isotope-labeled oral glucose tolerance test (SI-OGTT) incorporating complementary deuterium glucose tracers at a $1: 1$ ratio $\left(2-{ }^{2} \mathrm{H}\right.$-glucose and $6-6{ }^{2} \mathrm{H}$-glucose; $2 \mathrm{~g} / \mathrm{kg}$ lean body mass) to distinguish between endogenous glucose production (EGP) and whole-body glucose disposal. SI-OGTT was performed in C57BL/6J mice after $8 \mathrm{wk}$ on a high-fat diet (HFD; $45 \%$ fat). Mice were then randomized to either a wheel-running cage $(n=13$, HFD Ex) or a normal cage ( $n=13$, HFD Sed) while maintaining the HFD for $4 \mathrm{wk}$ before performing a SI-OGTT. HFD Ex mice demonstrated improvements in whole blood glucose total area under the curve (AUC) that was attributed primarily to a reduction in EGP AUC. Serum insulin levels measured at 0 and 15 min post- glucose gavage were significantly elevated in the HFD Sed mice, whereas HFD Ex mice demonstrated the expected reduction in insulin at both time points. Overall, exercise improved hepatic insulin sensitivity by reducing postprandial EGP, but also increased whole-body glucose disposal. Finally, these results demonstrate the benefits of exercise on hepatic insulin sensitivity by combining a more physiological route of glucose administration (oral glucose) with the resolution of stable isotope tracers. These novel observations clearly demonstrate that SI-OGTT is a sensitive and cost-effective method to measure exercise adaptations in obese mice with as little as $2 \mu$ l of tail blood.
\end{abstract}

exercise; glucose tolerance; stable isotopes; voluntary wheel running

\section{INTRODUCTION}

Pre-diabetes and type 2 diabetes (T2D) are characterized by fasting and postprandial hyperglycemia (6). Under physiological postprandial conditions, increased blood glucose concentrations stimulate insulin secretion to reduce endogenous glucose production (EGP), enhance muscle glucose uptake, and reduce adipose tissue lipolysis in a coordinated manner to dispose of exogenous glucose and restore euglycemia. Persistent hyperglycemia, in both the fasting and postprandial state, are thought to be responsible for the increased prevalence of vascular disease in subjects with T2D (34). Notably, it appears that individuals with normal fasting glucose yet impaired glucose tolerance (IGT; pre-diabetes) already demonstrate

Correspondence: T. D. Allerton (timothy.allerton@pbrc.edu). signs of endothelial dysfunction and other diabetes related complications (1). Therefore, strategies for improving postprandial glucose metabolism are important for not only preventing the development of overt T2D but also for preventing the complications of pre-diabetes.

Exercise is an effective strategy to increase insulin sensitivity and glucose tolerance in humans and animal models of diet-induced obesity (DIO) and insulin resistance (16). Voluntary wheel running (VWR) is an exercise model $(13,14)$ utilized to promote common exercise-mediated skeletal muscle adaptations (i.e., mitochondrial content and function) (31). Data from exercised rats shows consistent results for improved whole body insulin sensitivity, but inconsistent benefits on tissue-specific (i.e., muscle and liver) insulin sensitivity (11, 12, 23, 30). Furthermore, while it is well known that VWR can restore glucose tolerance in DIO mice $(3,5,41)$, there is little mechanistic insight into the actual metabolic pathways responsible for the improvements in postprandial glucose handling in this commonly used exercise model.

Dynamic glucose disposal is dependent on whole body coordination of insulin action and insulin secretion, which more accurately represent the transition from the fasted to fed state $(43,44)$. DIO mice are known to develop hyperglycemia and hyperinsulinemia and therefore present a model of insulin resistance $(29,46)$. The euglycemic hyperinsulinemic clamp method is a valuable tool to measure insulin action; however, it fails to replicate dynamic endogenous hormone alterations that occur during nutrient intake and may fail to elucidate undetectable metabolic phenotypes (43). Furthermore, the clamp method is an invasive procedure that does not lend itself to repeated measures over time (25). Also, the technical expertise and demands of the methodology have greatly limited its availability. Therefore, the aim of the current study was to measure glucose dynamics in a common metabolic model, DIO in C57BL/6J mice, before and after a period of VWR. We also interrogated molecular signatures of exercise-induced adaptations in skeletal muscle and liver that have been implicated in improved glucose handling.

\section{MATERIALS AND METHODS}

Animal housing and study design. The Pennington Biomedical Research Center (PBRC) Animal Care and Use Committee approved all study experiments. Four-week-old male C57BL/6J mice $(n=26)$ were purchased (The Jackson Laboratory, Bar Harbor, ME) and housed in the PBRC comparative biology core. Mice (4 wk old) were then multihoused (4 to a cage) and placed on a $45 \%$ high fat diet (HFD; Research Diet12451, New Brunswick, NJ) for 8 wk. Following the 8-wk HFD 
feeding period, mice were individually housed and randomly allocated to either a HFD sedentary group (HFD Sed), one to a cage, with no running wheel or a cage with free access to a running wheel (HFD Ex; Minimitter, West Chester, PA) for 4 wk. Wheel revolutions were counted each minute by a magnetic switch mechanism, and data were stored using Vital View Software (version 4.0, Oakmont, PA). Body weight and food intake were measured on a weekly basis. Food intake was assessed by weighing food put it in the food hopper and then weighing remaining food pellets and crumbs to determine the amount ingested (47). Body composition was measured via NMR, and a stable isotope-labeled oral glucose tolerance test (SI-OGTT) was performed to get an index of dynamic glucose disposal and pattern of endogenous glucose production both after 8 wk of HFD feeding (Pre) and again after $12 \mathrm{wk}$ HFD feeding (Post; i.e., after $4 \mathrm{wk}$ of exercise intervention). At the end of the experiment, mice were euthanized by isoflurane administration with cardiac puncture. A subgroup of mice ( $n=6$, HFD Sed; $n=5$, HFD Ex) from both groups was intraperitoneally injected with human insulin (Humulin, Eli Lilly, Indianapolis, IN) at a dose of $1.5 \mathrm{U} / \mathrm{kg} 10 \mathrm{~min}$ before euthanasia to examine modulation of insulin signaling proteins.

SI-OGTT. To get a readout of the dynamic changes in glucose disposal and patterns in endogenous glucose production (EGP), we employed a SI-OGTT consisting of two complementary deuterium glucose labels $\left(2-\left[{ }^{2} \mathrm{H}\right]\right.$ and $6,6-\left[{ }^{2} \mathrm{H}\right]$; Cambridge Isotope, Tewksbury, MA) at a $1: 1$ ratio as described previously (28). Briefly, mice were fasted for $4 \mathrm{~h}$ and were then gavaged with a 1:1 ratio of the glucose tracer at a total dose of $2 \mathrm{~g} / \mathrm{kg}$ lean body mass. Tail blood glucose was measured at $0,15,30,45,60,90$, and $120 \mathrm{~min}$ with a glucometer (Bayer, Leverkusen, Germany). Unlabeled, 2- $\left[{ }^{2} \mathrm{H}\right]$-glucose and 6,6$\left[{ }^{2} \mathrm{H}\right]$-glucose concentrations were measured at $0,15,30,60$, and 120 min via gas chromatography-mass spectrometry (GS-MS). Serum extraction was conducted in ice-cold analytic grade methanol to precipitate proteins. Samples were then vortexed and centrifuge spun at $3,000 \mathrm{rpm}$ at $4^{\circ} \mathrm{C}$ for $10 \mathrm{~min}$. The supernatant was then derivatized via a hydroxylamine hydrochloride solution and acetic anhydride to ensure complete acylation of hydroxyl groups. Fractional amounts of $\left(2-\left[{ }^{2} \mathrm{H}\right]\right.$ and 6,6- $\left[{ }^{2} \mathrm{H}\right]$ glucose tracers were determined via GC-MS and a matrix method, while tracer concentrations over time were calculated by using measured plasma glucose concentrations. The processing method required an initial plasma sample volume of $2.5 \mu \mathrm{L}$ combined with $100 \mu \mathrm{L}$ of chilled methanol to precipitate proteins. The samples were then centrifuged at $3,000 \mathrm{rpm}$ for $10 \mathrm{~min}$ at $4^{\circ} \mathrm{C}$ after which $85 \mu \mathrm{L}$ of the supernatant was transferred into a $400 \mu \mathrm{L}$ glass GC insert (Thermo Scientific, Rockwood, TN) and dried in a speed vacuum at $37^{\circ} \mathrm{C}$ for $1 \mathrm{~h}$ (Labconco). Samples were derivatized by adding $50 \mu \mathrm{L}$ of hydroxylamine hydrochloride (Sigma, St. Louis, MO) in pyridine $(30 \mathrm{mg} / 1 \mathrm{~mL})$, vortexed for $10 \mathrm{~s}$, and put in a $90^{\circ} \mathrm{C}$ oven for $1 \mathrm{~h}$. After the samples were removed from the oven and allowed to cool for $10 \mathrm{~min}, 50 \mu \mathrm{L}$ of acetic anhydride was added to the samples and they were incubated at $60^{\circ} \mathrm{C}$ for $30 \mathrm{~min}$ to ensure complete acylation of hydroxyl groups. Next, samples were dried down in a speed vacuum at $37^{\circ} \mathrm{C}$ for $1 \mathrm{~h}$. The dried samples were then resuspended in $150 \mu \mathrm{L}$ of butyl acetate for GCMS analysis using the Agilent 7890A Gas Chromatography system with a DB-5 capillary column installed ( $30 \mathrm{~m}, 0.25 \mathrm{~mm}, 0.25 \mu \mathrm{m}$, J\&W Scientific) and a 5975C inert XL EI/CI MSD with triple-axis detector (Agilent, Santa Clara, CA). The samples were analyzed via positive chemical ionization using helium as the carrier gas and methane as the reagent gas. Glucose enrichment was measured using molecular ions 328, 329, and $330 \mathrm{~m} / \mathrm{z}$, corresponding to naturally occurring glucose M0 (328), $\left[2-{ }^{2} \mathrm{H}\right]$ tracer M1 (329), and $\left[6,6-{ }^{2} \mathrm{H}\right]$ tracer M2 (330). Selective ion monitoring (SIM) was utilized with a $20-\mathrm{ms}$ dwell time for each ion. The samples were injected using the splitless mode with a constant flow of $1 \mathrm{~mL} / \mathrm{min}$ and a run time of $15 \mathrm{~min}$. Ion abundances were analyzed using the Quantitative Mass Hunter Workstation (Agilent). Values obtained from ion peak integration were used to calculate tracer fractional amounts and changes in concentration over time.
The use of stable isotope-labeled glucose permits the partitioning of the blood glucose concentration into the glucose derived from endogenous (unlabeled)- and exogenous meal-derived (labeled) sources (28). A common feature of T2D in human and rodents models is hepatic futile glucose cycling $(7,27)$. Whereby glucose is normally phosphorylated via glucokinase and trapped in the hepatocyte by investment of energy (1 ATP), hepatic futile glucose cycling reflects the dephosphorylation of glucose by glucose-6-phosphatase and subsequent release back into the circulation. The isotopic position of $\left[2-{ }^{2} \mathrm{H}\right]$-glucose can be recycled and positioned on glucose leaving the hepatocyte. Whereas, $\left[6,6-{ }^{2} \mathrm{H}\right]-$ glucose generally reflects glucose disposal because the ${ }^{2} \mathrm{H}$ will not be recycled back into the $\mathrm{C}-6$ position (36). When provided in equimolar amounts, the dual tracer approach can detect hepatic futile glucose cycling by measuring the difference in $\left[2-{ }^{2} \mathrm{H}\right]$ glucose area under the curve (AUC) from the AUC $\left[6,6-{ }^{2} \mathrm{H}\right]-$ glucose $(27,28)$.

Preparation of tissue extracts. At the time of necropsy, adipose tissues, gastrocnemius muscle, and the liver were collected, weighed, and frozen. Triacylglycerol (TAG) were measured in serum, muscle, and the liver using a colorimetric assay (Eagle Biosciences, Amherst, $\mathrm{NH}$ ). Liver and muscle glycogen were processed by enzymatic hydrolysis and measured via a colorimetric assay (Abcam, Cambridge, MA). Serum nonesterified fatty acids (NEFA) were quantified by the Acyl-CoA oxidase method (Wako Chemical, Richmond, VA). Serum insulin was measured by ELISA (Biovision, Milpitas, CA). The homeostatic model analysis of insulin resistance (HOMA-IR) was calculated by serum insulin $(\mathrm{mmol} / \mathrm{L}) \times$ blood glucose $(\mathrm{mmol} / \mathrm{L}) /$ 22.5 .

Protein and mRNA expression. Gastrocnemius and liver tissues were powdered using a frozen mortar and pestle and homogenized in a protein extraction buffer containing $150 \mathrm{mM} \mathrm{NaCl}, 10 \mathrm{mM}$ Tris ( $\mathrm{pH}$ 7.4), 1 mM EDTA, 1 mM EGTA, 0.5\% IGEPAL CA-630, 1\% Triton $\mathrm{X}-100,2 \mathrm{mM}$ PMSF, $2 \mu \mathrm{M}$ pepstatin, 100 trypsin inhibitory $\mathrm{mU}$ of aprotinin, $20 \mu \mathrm{M}$ leupeptin, $2 \mathrm{mM} \mathrm{1,10-phenanthroline,} 0.8 \mathrm{mM}$ sodium orthovanadate, and $400 \mu \mathrm{M}$ sodium fluoride. Tissue homogenates were then clarified using centrifugation at $13,000 \mathrm{~g}$ for $10 \mathrm{~min}$ at $4^{\circ} \mathrm{C}$ and stored at $-80^{\circ} \mathrm{C}$ until analysis.

For RNA extraction, powdered tissues were homogenized in TRIzol (Life Technologies, Carlsbad, CA) followed by isolation using standard phenol-chloroform extractions. RNA was then isolated using the RNeasy Mini Kit (Qiagen, Hilden, Germany) and stored at $-80^{\circ} \mathrm{C}$ until further analysis.

Immunoblotting. Protein concentrations from tissue homogenates were quantified using a BCA Kit for Protein Determination (SigmaAldrich, St. Louis, MO). A total of 50-100 $\mu \mathrm{g}$ of protein were loaded on 10\% SDS-polyacrylamide gels (National Diagnostics, Atlanta, GA) and transferred onto $0.45 \mu \mathrm{m}$ nitrocellulose membranes (BioRad, Hercules, CA). Membranes were blocked with $4 \%$ milk for $1 \mathrm{~h}$ at room temperature and probed with antibodies listed in Table 1 overnight at $4^{\circ} \mathrm{C}$. Proteins were detected using horseradish peroxidase-conjugated secondary antibodies (Jackson ImmunoResearch, West Grove, PA) and SuperSignal West Pico PLUS reagents (Thermo Fisher, Rockford, IL). Blots were imaged using X-ray film or the ChemiDoc XRS + Imaging System (Bio-Rad). Protein signals were

Table 1. List of antibodies used for immunoblotting

\begin{tabular}{lll}
\hline \hline \multicolumn{1}{c}{ Supplier } & \multicolumn{1}{c}{ Antibody } & \multicolumn{1}{c}{ Source } \\
\hline Cell Signaling & $\mathrm{AKT}$ & Mouse monoclonal \\
Cell Signaling & $\mathrm{AKT}^{\mathrm{pS} 473}$ & Mouse monoclonal \\
Cell Signaling & $\mathrm{AKT}$ & Rabbit polyclonal \\
Cell Signaling & $\mathrm{AMPK} \alpha$ & Rabbit polyclonal \\
Cell Signaling & $\mathrm{AMPK} \alpha^{\mathrm{pT} 172}$ & Rabbit polyclonal \\
Abclonal & $\mathrm{PDK} 4$ & Rabbit polyclonal \\
R\&D Systems & $\mathrm{STAT5B}$ & Rabbit polyclonal \\
\hline
\end{tabular}


Table 2. Primer sequences for mRNA determination

\begin{tabular}{|c|c|c|}
\hline Gene & Forward Primer & Reverse Primer \\
\hline Foxol & CTTCAAGGATAAGGGCGACAG & AGTTCCTTCATTCTGCACTCG \\
\hline$M d h 1$ & GGCACAGCCTTGGAGAAATA & CTGGATACTGGGTCGATGAATG \\
\hline Nos3/Enos & CTTGAGGATGTGGCTGTGT & TGGTCCACTATGGTCACTTTG \\
\hline Pdk4 & CATCGCCAGAATTAAACCTCAC & GGCATTCTTGAAGAGTTCGAAG \\
\hline Pepck/Pck1 & GCCGAGACTAGCGATGGGGGT & TGGGCACATGGTTCCGCGTC \\
\hline Tfam & AAACCAAAAAGACCTCGTTCAG & TTTCCAAGCCTCATTTACAAGC \\
\hline$U b b$ & CCAGTGGGCAGTGATGG & GCTTACCATGCAACAAAACCT \\
\hline
\end{tabular}

Cs, citrate synthase; Foxo1, Forkhead Box O-1; Mdh1, malate dehydrogenase 1; Mdh2, malate dehydrogenase 2; NOS3, nitric oxide synthase; Pdk4, pyruvate dehydrogenase kinase 4; Peck, phosphoenolpyruvate carboxykinase; Pgcl $\alpha$, peroxisome proliferator-activated receptor gamma coactivator 1-alpha; TFAM, mitochondrial transcription factor A; Ppia, peptidylprolyl isomerase A; Ubb, ubiquitin b.

quantified in either Image Studio 5.2 (LI-COR Biosciences, Lincoln, NE) or Image Laboratory 4.0 (Bio-Rad).

Gene expression analysis. RNA concentrations were quantified using a NanoDrop ND-1000 UV-Vis Spectrophotometer. Reverse transcription was performed using a High-Capacity cDNA Reverse Transcription Kit (Applied Biosystems, Foster City, CA) with $2 \mu \mathrm{g}$ of RNA. Quantitative PCR was performed using SYBR Premix with ROX Plus (Takara Bio, Mountain City, CA) with 4 ng of cDNA and run on the Applied Biosystems 7900HT system with SDS 2.4 software (Applied Biosystems). Thermal cycling conditions were as follows: 2 min at $50^{\circ} \mathrm{C}, 10 \mathrm{~min}$ at $95^{\circ} \mathrm{C}, 40$ cycles of $15 \mathrm{~s}$ at $95^{\circ} \mathrm{C}$, and $1 \mathrm{~min}$ at $60^{\circ} \mathrm{C}$; dissociation stage: $15 \mathrm{~s}$ at $95^{\circ} \mathrm{C}, 15 \mathrm{~s}$ at $60^{\circ} \mathrm{C}$, and $15 \mathrm{~s}$ at $95^{\circ} \mathrm{C}$. Relative expression of genes were interpolated using standard curves, and all target genes were normalized to the numerical average of Ppia (peptidyl prolyl isomerase A) and $U b b$ (ubiquitin B). The primers (Integrated DNA Technologies, Coralville, IA) are found in Table 2.

Statistical analysis. An independent $t$ test and repeated measures two-way ANOVA were utilized to analyze data where appropriate (Prism, Graphpad). Multiple comparisons were made by HolmSidak's test. Statistical significance was declared at $P<0.05$. All data were reported as means $\pm \mathrm{SE}$. Calculations of incremental AUC were made by the trapezoidal method.

\section{RESULTS}

Body composition. At 4 wk of age, a group of 26 male mice were group housed (4 to a cage) and placed on a 45\% HFD for 8 wk. Following the 8-wk HFD feeding period, mice were individ-
A

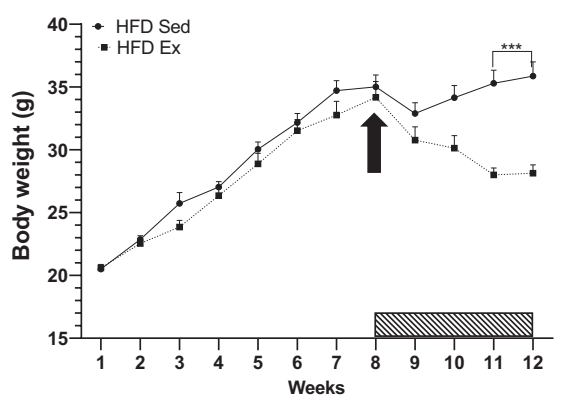

D

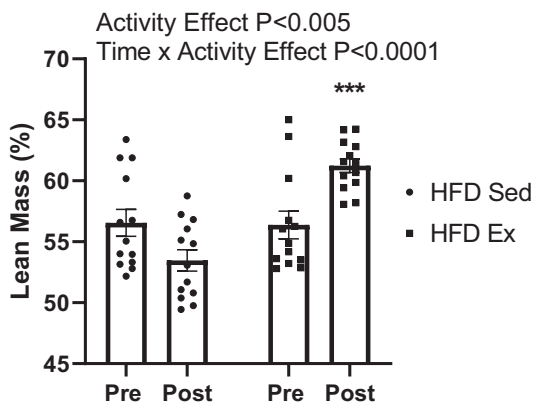

B

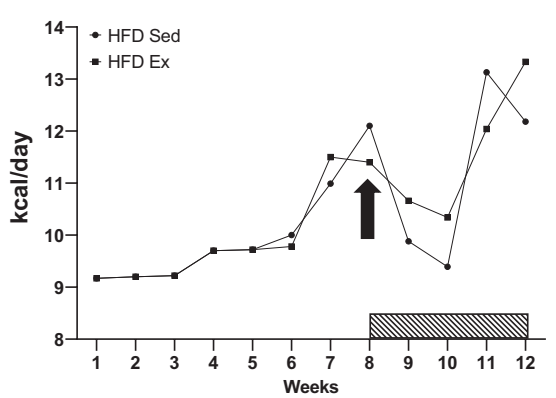

E

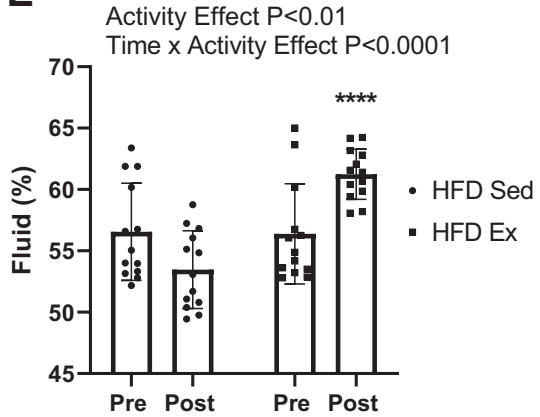

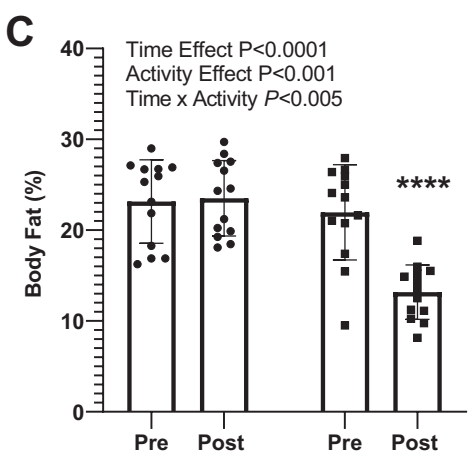

$\mathbf{F}$

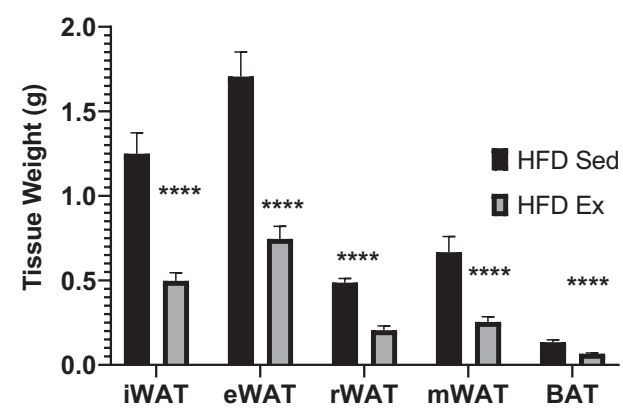

Fig. 1. Voluntary wheel running (exercise) reduces fat mass. Four-week-old C57BL/6J male mice (group-housed) were placed on a $45 \%$ high-fat diet (HFD) for $8 \mathrm{wk}$. Mice were randomized and single housed in sedentary (Sed) or wheel running (Ex; bar with hashed lines) conditions for an additional 4 wk (12 wk total). Body weight was measured weekly over the 12-wk experiment $(A)$ as was food intake $(B)$. NMR was utilized to measure body fat percentage $(C)$, lean mass $(D)$, and body fluid $(E) . F$ : adipose tissue mass weights for inguinal (iWAT), epididymal (eWAT), mesenteric (mWAT), and reteroperitoneal (rWAT) white adipose tissue. $E$ : time effect refers to difference between pre- and postmeasurements. Activity effect refers to difference between Sed and Ex mice. Time $\times$ activity indicates an interaction. All data are expressed as means \pm SE. $* * * P<0.001, * * * * P<0.0001 ; n=13 /$ group. 
ually housed and randomly allocated to either a HFD page wheel or a cage with free access to a running wheel (HFD Ex) for 4 wk. HFD Ex mice had a significant reduction in body weight (Fig. 1A) that was not due to a significant difference in food intake between the exercise and sedentary mice (Fig. $1 B$ and Supplemental Fig. S1; https://doi.org/10.6084/m9.figshare.12170451.v1). Percent body fat decreased when mice transitioned from a sedentary ( $21.9 \%$ body fat, week 8, Pre) to exercised (13.1\% body fat, week 12, Post) condition (Fig. 1C). Yet, the HFD Sed group had no change in fat mass over the 4-wk period (pre, $23.1 \%$ to Post, 23.5\%). Lean mass (Fig. 1D) and fluid mass (Fig. 1E), when expressed as a percentage of total body weight, was increased in HFD Ex mice (+4.8\%) compared with HFD Sed mice $(-3.0 \%)$. All adipose tissue depots were reduced in mass in mice following VWR compared with sedentary controls (Fig. $1 F$ ). On average HFD Ex mice ran $5.8( \pm 1.7) \mathrm{km} /$ day with a range of 4.3 to 8.5 $\mathrm{km} /$ day. Time effects refer to differences between Pre and Post measurements. Activity effects refer to differences between Sed and Ex mice. Time $\times$ activity indicates an interaction.

Glucose tolerance. To assess glucose dynamics, we performed an OGTT with two stable isotopes (SI). The SI-OGTT can distinguish between exogenous glucose and endogenous sources of glucose. A typical OGTT is shown in Fig. 2A, where glucose measurements were assessed with a glucometer and represents both labeled and unlabeled glucose. As shown in Fig. $2 B$, whole blood glucose AUC following the SI-OGTT was not different between the HFD Sed and HFD Ex before randomization at $8 \mathrm{wk}$ (Pre). However, following the 4-wk VWR intervention, exercised mice had a significant reduction in the glucose AUC compared with the sedentary controls. Serum insulin measured at time 0 and $15 \mathrm{~min}$ after glucose gavage did not differ between groups before randomization (Fig. 2C). Yet, insulin levels were reduced in the HFD exercised mice compared with sedentary conditions (Fig. 2C). Serum NEFA levels were not different between the sedentary and exercised groups both pre- and postintervention (Fig. 2D). As expected, HOMA-IR was significantly $(P<0.001)$ reduced in the exercised group (Fig. 2E).

SI-OGTT. The utilization of complementary stable isotope tracers $2-\left[{ }^{2} \mathrm{H}\right]$-glucose and $6,6-\left[{ }^{2} \mathrm{H}\right]$-glucose allows for the ability to separate administered glucose (labeled glucose) vs. endogenous glucose (unlabeled glucose) and provides an index of the suppression of endogenous glucose production (EGP) and dynamic glucose disposal. Before randomization (Pre), there were no differences for endogenous glucose, $2-\left[{ }^{2} \mathrm{H}\right]-$ glucose and 6,6- $\left[{ }^{2} \mathrm{H}\right]$-glucose AUC between the two groups of mice (Fig. 3, $A-C$ ). However, HFD exercised mice had a reduction in endogenous glucose AUC (Pre vs. Post) and between groups of mice (exercised vs. sedentary). After conducting a repeated measures two-way ANOVA, we detected significantly lower endogenous glucose levels at the 0-, 60-, and 120-min time points for the glycemic fluctuations (Fig.
A

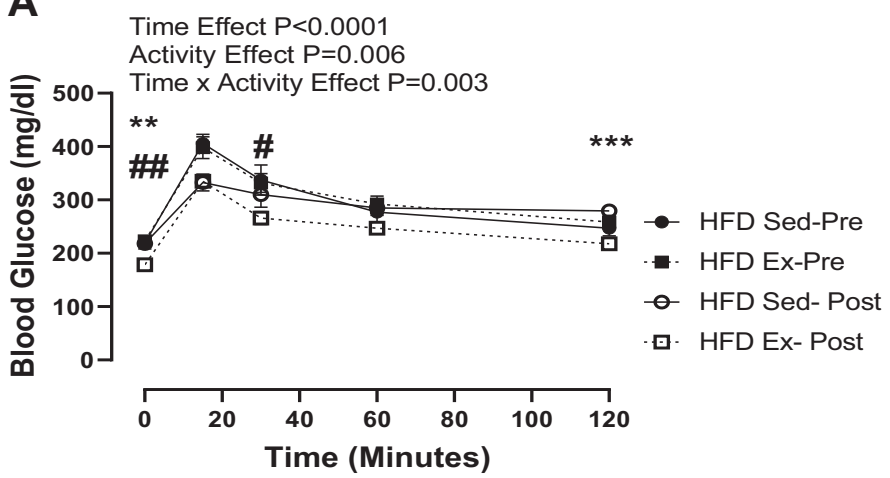

B

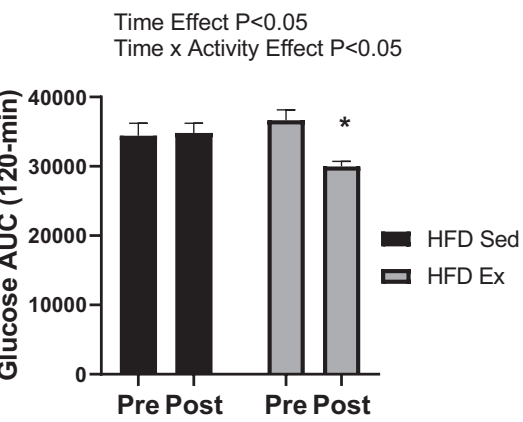

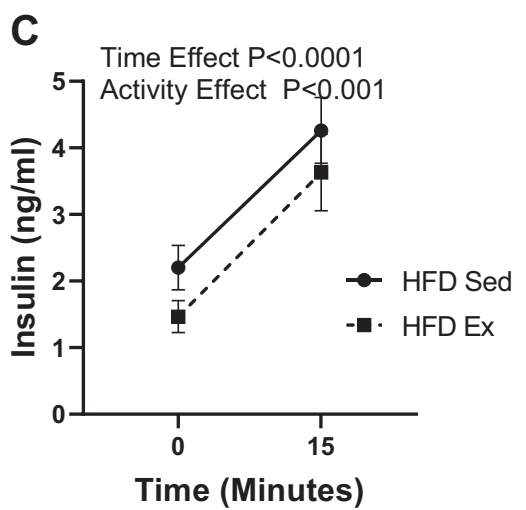
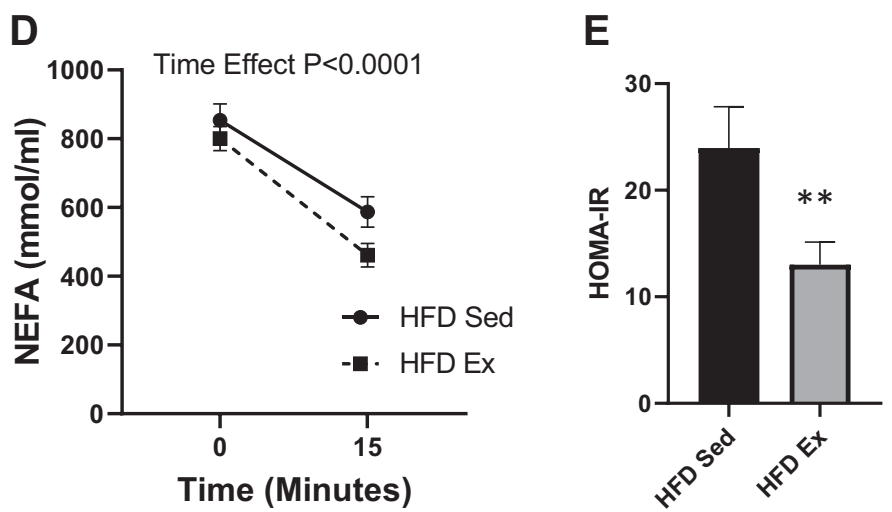

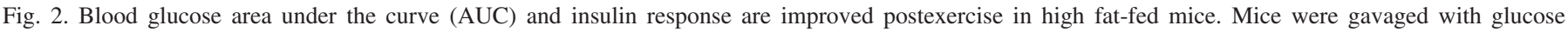

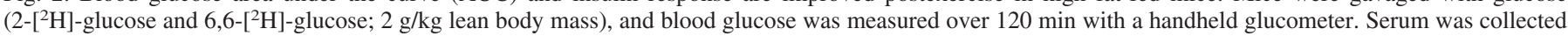

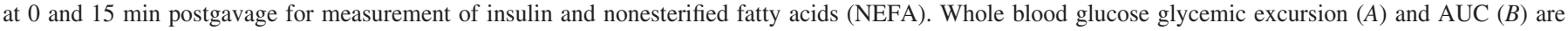

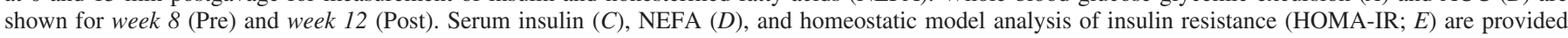

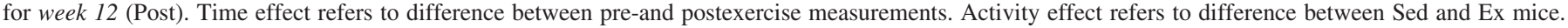

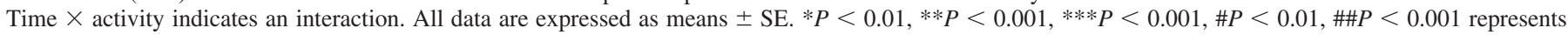
within-group effects; $n=13$ /group. 
A
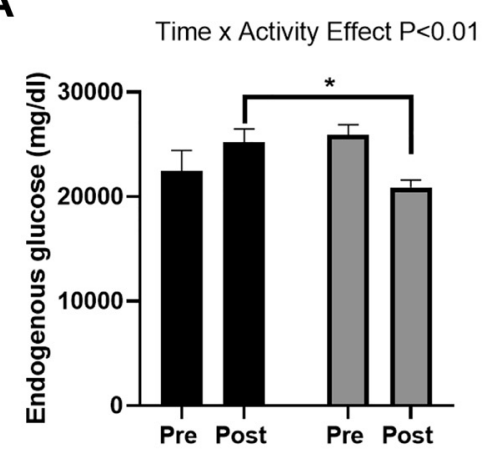

D

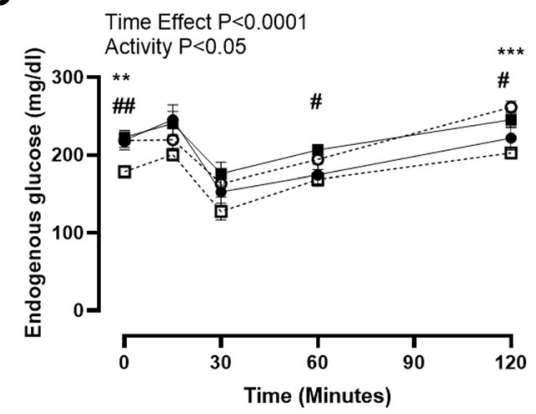

B

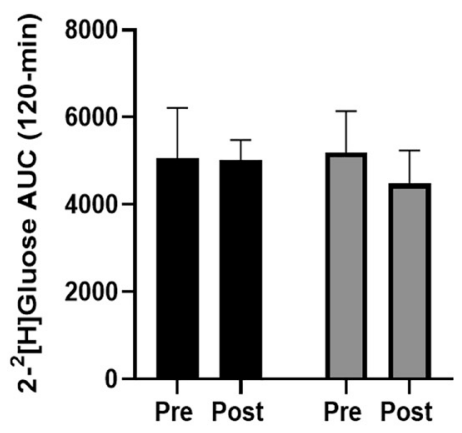

E

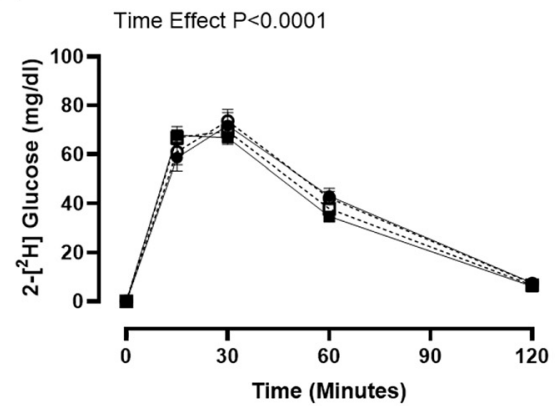

C

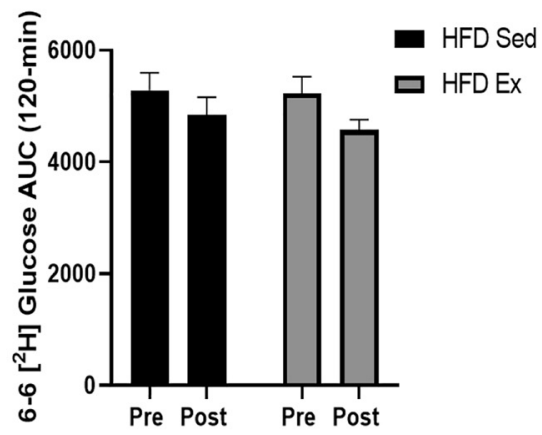

$\mathbf{F}$

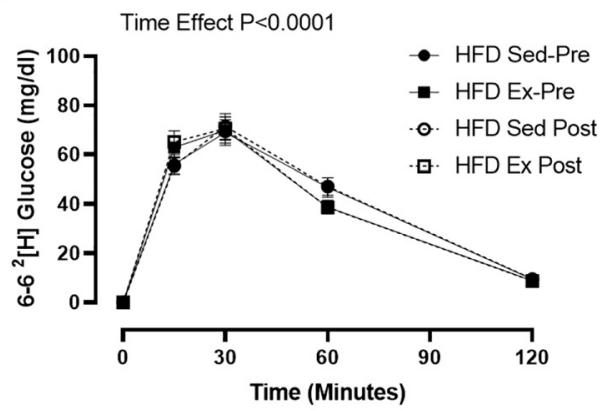

G

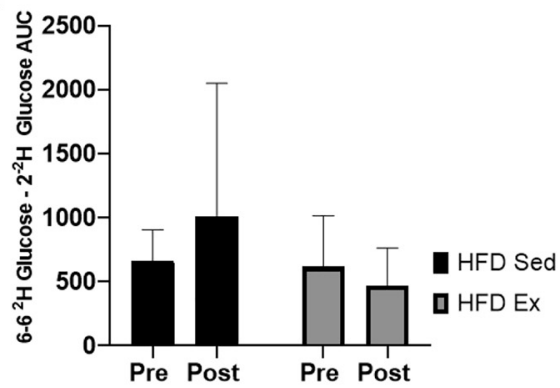

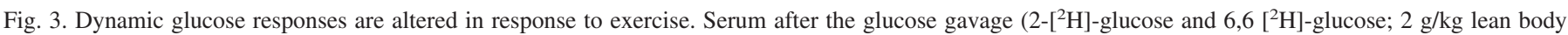

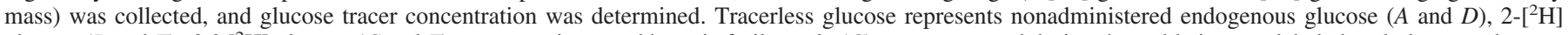

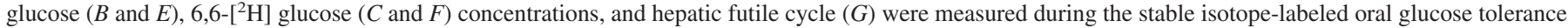

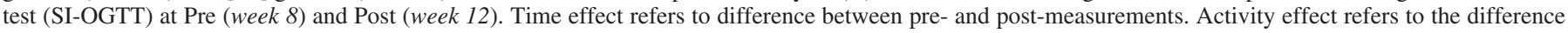

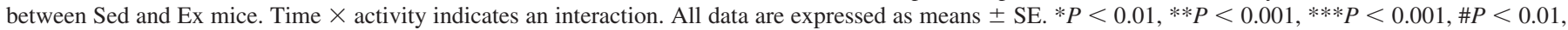
$\# \# P 0.001$, within-group effect; $n=13 /$ group.

$3 D)$. The shape of the endogenous glucose excursion curve where it dips between 15 and 30 min post- glucose gavage coincides with the progressive increase in exogenous, isotopically labeled glucose. This is also the period when insulin secretion increases (Fig. 2C), demonstrating the capacity, albeit low, for insulin to suppress hepatic glucose release. There were no significant differences between groups in the measurement of 2- $\left[{ }^{2} \mathrm{H}\right]$-glucose and $6,6-\left[{ }^{2} \mathrm{H}\right]$-glucose AUC and glycemic fluctuations (Fig. 3, $A$ and $E$ and $B$ and $F$, respectively). Hepatic futile glucose cycling was measured by subtracting the AUC for 2-[ $\left.{ }^{2} \mathrm{H}\right]$-glucose from 6 to $6-\left[{ }^{2} \mathrm{H}\right]$-glucose AUC (Fig. $3 G)(25)$. We did not detect any significant effects for time $(P=0.85)$ or for group $(P=0.58)$

Serum and tissue triglycerides and glycogen. VWR results in a significant reduction in triacylglycerol (TAG) levels in serum (Fig. 4A) and the liver (Fig. 4B) compared with sedentary controls. Conversely, muscle TAG levels were increased, but not significant, in HFD Ex vs. Sed mice (Fig. 4C). Notably, there was a compelling trend for a reduction in liver glycogen content $(P<0.057)$ in exercised mice compared with sedentary controls. However, there were no differences detected in skeletal muscle (mixed gastrocnemius muscle) glycogen content between the two groups (Fig. 4E).

Protein abundance and gene expression. Ten minutes before euthanasia, mice in each were group were injected with vehicle (HFD Sed, $n=7$; HFD Ex, $n=8$ ) or insulin (HFD Sed, $n=$ 6; HFD Ex, $n=5$ ). Insulin sensitivity was assessed in skeletal muscle (gastrocnemius) and the liver by examining acute insulin induction of Akt phosphorylation. As shown in Fig. $5 A$, there was a significant in both HFD Sed mice $(P=0.002)$ and HFD Ex mice $(P=0.01)$ increase in phosphorylation of Akt $\left(\mathrm{Akt}^{\mathrm{S} 473}\right)$ following acute insulin treatment. Insulin induction of liver Akt phosphorylation was significantly increased in HFD Ex mice $(P=0.05)$, but not HFD Sed mice $(P=0.80)$ 

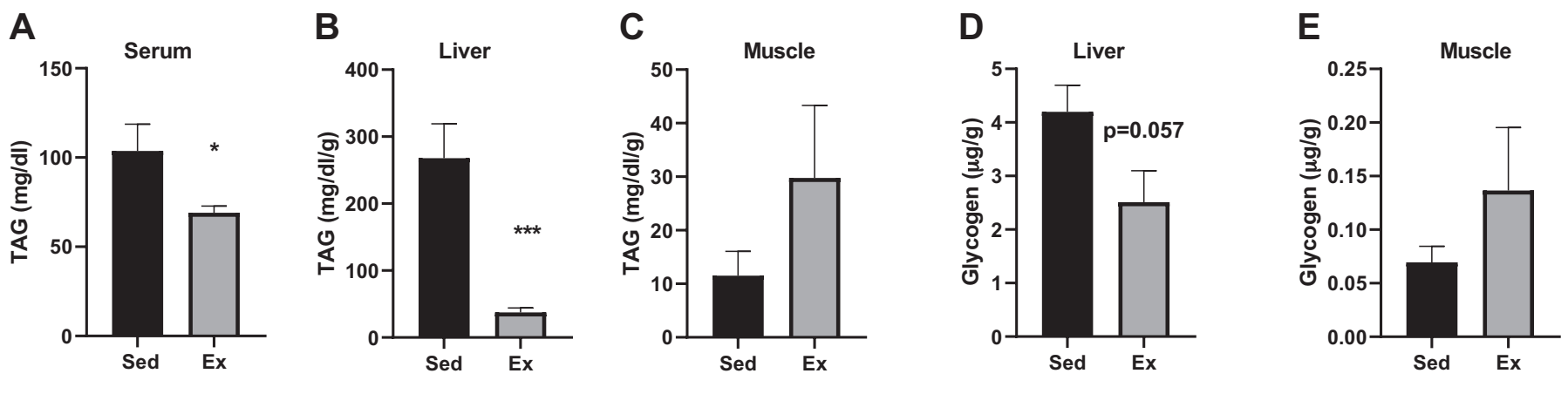

TAG

\section{Glycogen}

Fig. 4. Muscle glycogen is increased, while liver glycogen is decreased in response to voluntary wheel running. Serum triglycerides (TAG), muscle, and liver extracts were measured for TAG and glycogen after $4 \mathrm{wk}$. The effect of $4 \mathrm{wk}$ of exercise on serum $(A)$, liver $(B$ and $D)$, and muscle $(C$ and $E)$ TAG and glycogen content. All data are expressed as means \pm SE. $* P<0.01$, $* * * P<0.001 ; n=8 /$ group.

(Fig. 5C). Basal phosphorylation of AMPK (AMPK ${ }^{\text {Thr172 }}$ ) in skeletal muscle was significant elevated in $\operatorname{HFD}$ Ex mice $(P=$ 0.002) compared with HFD Sed mice (Fig. 5B). There was no difference in liver pAMPK between groups $(P=$ HFD Sed vs. HFD Ex, $P=0.18$ ) (Fig. 5D). Muscle PDK4 protein abundance tended to be increased in exercised mice, but did not reach statistical significance $(P=0.09)$ (Fig. 5B). Liver PDK4 levels were not significantly different between the groups $(P=$ 0.29 ) (Fig. 5D). PDK4 migrates at $42 \mathrm{kDa}$, indicated by the arrow in the figure, but we did find a nonspecific band at 38
$\mathrm{kDa}$ in both gastrocnemius and liver samples (Fig. 5, $B$ and $D$ ). STAT5B expression was used as a loading control. These muscle and liver samples were also used for gene expression analysis (Fig. 6). The mRNA levels of endothelial nitric oxide synthase (eNOS; $P<0.05$ ), malate dehydrogenase 1 (mdh1; $P<0.0001$ ), and citrate synthase (CS; $P<0.001$ ) were significantly increased in mixed gastrocnemius muscle. In the liver, there was a notable increase in FOXO1 $(P<0.001)$ and a decrease in Pdk4 mRNA levels in exercised mice compared with sedentary controls.

\section{A Gastroc}

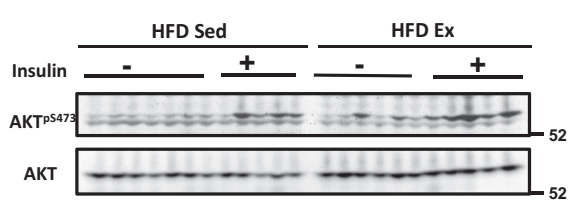

\section{Liver}

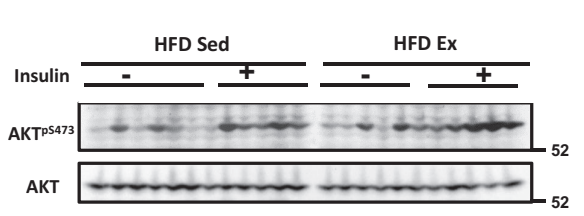

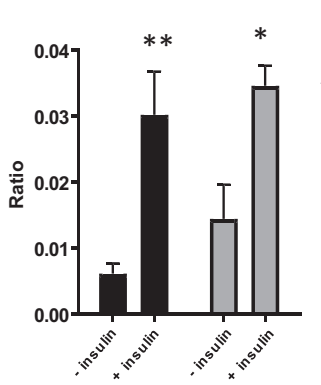

D Liver

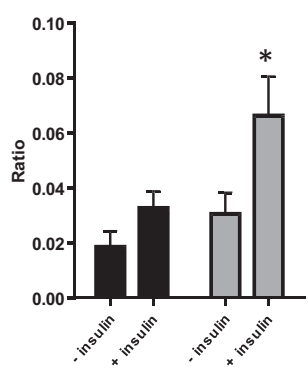

\section{B Gastroc}
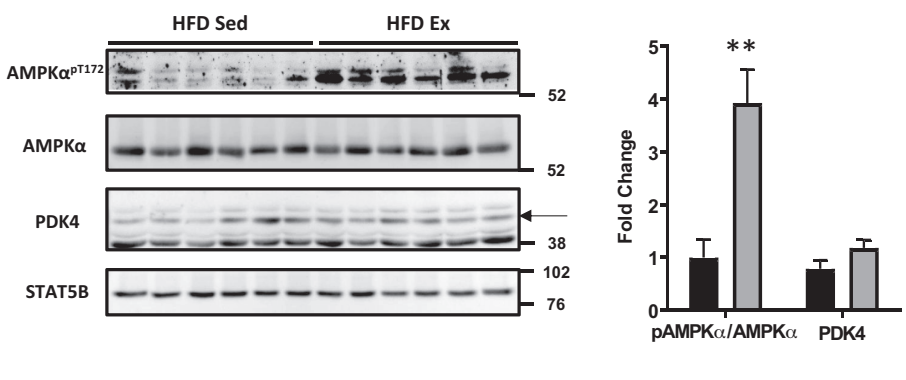

HFD Sed
$\square$ HFD Ex
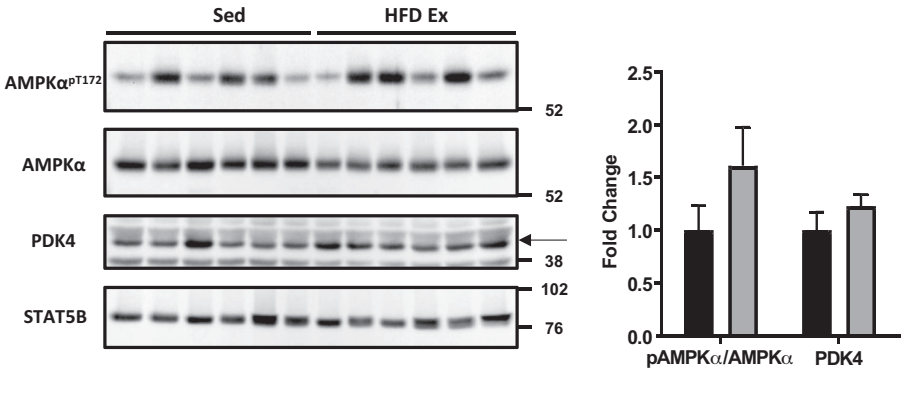

Fig. 5. Effect of voluntary wheel running on expression of insulin signaling proteins in skeletal muscle and liver. Whole tissue extracts were subjected to immunoblotting [mixed gastrocnemius (Gastroc) and liver] to detect changes in total levels of PDK4 and in the ratio of phosphorylated Akt to Akt (AktSer ${ }^{473} / \mathrm{Akt}$; \pm insulin injection) and basal AMPK phosphorylation at threonine 172 to total AMPK (pAMPK/AMPK). Five to six samples per group are shown in representative images, for pAkt/Akt and $n=6-$ insulin $/ n=6+$ insulin for high-fat diet (HFD) sedentary (Sed) and $n=6-$ insulin $/ n=$ $5+$ insulin for HFD wheel running (Ex) mice. For pAMPK/AMPK and PDK4, $n=6$ for both groups were used for quantification of band intensity shown in the graphs to the right of blots. STAT5B and $\alpha$-tubulin were used as loading controls. Data for Akt are expressed as a ratio and AMPK and PDK as fold-change $(* P<0.01, * * P<0.001)$. 

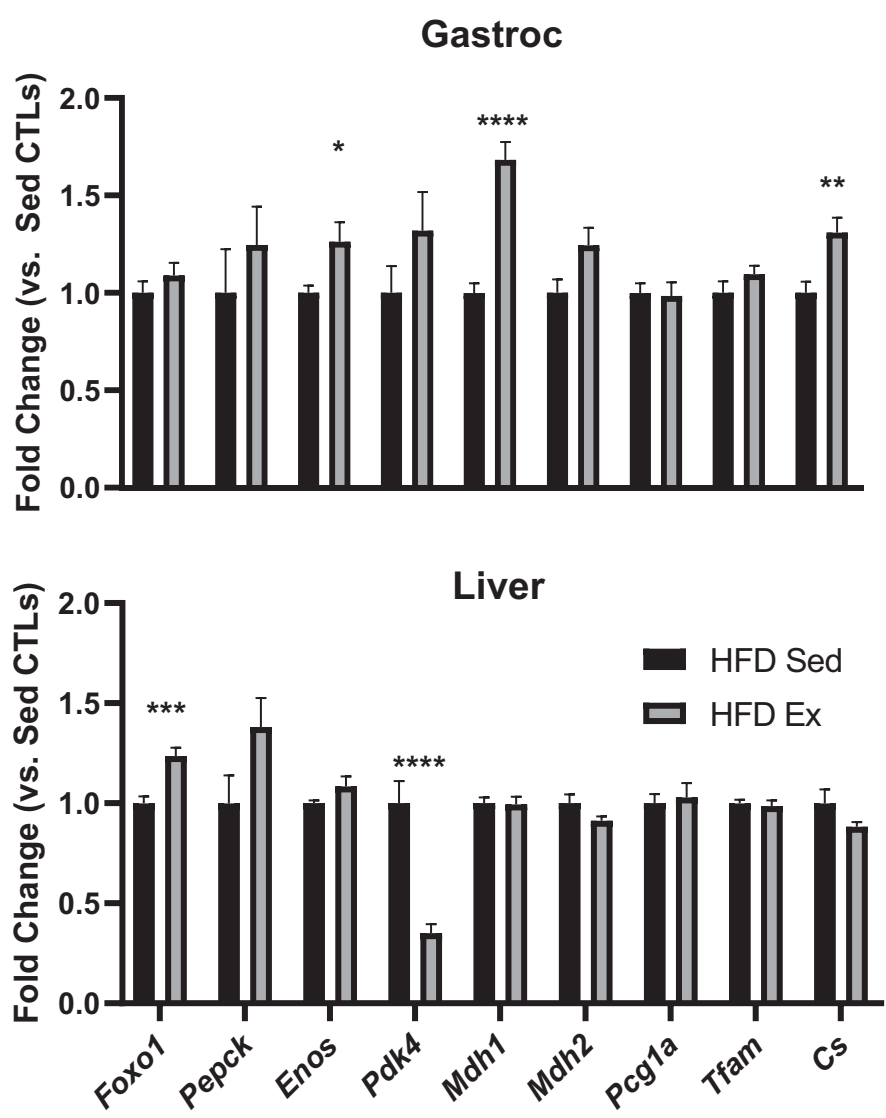

Fig. 6. Exercise decreases PDK4 and increases FOXO1 gene expression in liver, but not muscle, in high fat-fed (HFD) mice. Total RNA was isolated from mixed gastrocnemius (Gastroc) and liver tissues. Total RNA was isolated from frozen tissue samples and subjected to RT-qPCR to examine a panel of genes involved in gluconeogenesis, metabolic flexibility, and mitochondrial function. All data are expressed as fold-change vs. sedentary controls (Sed CTLs) \pm SE. $* P<0.01, * * P<0.001, * * * P<0.001$, **** $P<0.0001 ; n=8$ /group

\section{DISCUSSION}

Regular aerobic exercise improves muscle glucose uptake and insulin sensitivity in humans with T2D $(16,45)$. In rodent models of DIO, consumption of a HFD and the accompanying increase in adiposity leads to an insulin-resistant/glucose-intolerant state (46). VWR is commonly utilized to replicate exercising training due its unforced nature and propensity for mice to run between 5 and $10 \mathrm{~km} /$ day (32). Daily VWR can improve many aspects of metabolic health in high fat-fed mice and rats. However, to date, only a few reports have been published regarding VWR and insulin sensitivity as measured by the euglycemic-hyperinsulinemic clamp method in DIO rats $(11,12,23,30)$, with no reports in the VWR-trained high fat-fed C57BL/6J mice. Furthermore, there are no studies examining the adaptations over time that occur in dynamic glucose disposal in rodent-models of DIO in response to wheel running. Therefore, we sought to measure dynamic glucose disposal using two complementary stable isotopes of deuterium glucose $\left(2-\left[{ }^{2} \mathrm{H}\right]-\right.$ glucose and $6,6-\left[{ }^{2} \mathrm{H}\right]$-glucose) to measure dynamic glucose disposal in response to $4 \mathrm{wk}$ of VWR in a DIO mice.

There are discrepancies in the literature regarding the impact of VWR on body weight/body fat reduction in DIO mice (21, 33). In our study, we observed a significant reduction in body weight after 3 and 4 wk of VWR in high fat-fed mice compared with sedentary controls (Fig. 1A). The reduction in body weight was accompanied by a reduction in the percentage body fat between the sedentary and exercised mice (Fig. 1C). Also, percent lean body mass was higher in exercised mice after 1 mo but did not differ compared with absolute lean mass (Fig. $1 D)$. We did not measure any significant differences in food intake (Fig. $1 B$ ) between the two groups over the course of the study. Hence, the increased energy expenditure that occurs with VWR without a compensatory increase in food intake likely explains the overall differences we observed in body mass and composition.

Despite apparent fasting and postprandial hyperinsulinemia (Fig. 2A), sedentary mice had both increased fasting and OGTT blood glucose levels compared with the exercised group. The major advantage of using the SI-OGTT is that it permits the blood glucose concentration to be partitioned into what is derived from exogenous (oral glucose) and endogenous (produced by liver and kidneys) sources, permitting an index of glucose disposal and pattern of EGP to be estimated. 2-[ $\left.{ }^{2} \mathrm{H}\right]$-glucose is subjected to hepatic futile cycling, whereas $6,6-\left[{ }^{2} \mathrm{H}\right]$-glucose is not. Therefore, we were able to measure glucose disposal and hepatic futile cycling. We did not detect a large degree of hepatic futile cycling in sedentary or exercised mice (Fig. 3G). This is consistent with previous reports showing long duration (42 wk) feeding of a HFD, high-sucrose diet was necessary to induce hepatic futile cycling $(28,29)$. It is possible that the $45 \%$ HFD used in the current study is not a sufficient metabolic challenge to induce a loss of hepatic efficiency. Therefore, future implementation of this aspect of the SI-OGTT may be more appropriate for animals undergoing more severe metabolic challenges for longer periods of time. For comparison of glucose disposal and endogenous glucose, the sole use of $6,6-\left[{ }^{2} \mathrm{H}\right]$-glucose, without $2-\left[{ }^{2} \mathrm{H}\right]$-glucose, will provide valuable information in less severe models of insulin resistance.

Acute and chronic exercise improve insulin sensitivity in both human and animal models $(10,16,39)$. Improved insulin sensitivity in the immediate and extended time period after exercise $(3-4 \mathrm{~h})$ is thought to be linked to reduced skeletal muscle glycogen content $(9,39)$. Chronic exercise adaptations are thought to occur via more effective intracellular insulin signaling and improved mitochondrial capacity to oxidize lipids, thereby reducing substrate competition in skeletal muscle $(4,17,25)$. Interestingly, after 4 wk of wheel running, exercised mice did not have significant alterations in muscle glycogen levels; however, there was a strong trend $(P=0.057)$ for lower liver glycogen content (Fig. 4D). Our observations are consistent with other studies showing that VWR reduced liver glycogen content in a dose-dependent (volume of daily wheel running per day) manner (10). The exercise mice in our study did demonstrate a significant improvement in insulin sensitivity as evaluated by HOMA-IR (Fig. 2E). Since HOMA-IR incorporates fasted blood glucose and insulin levels, these observations also support an improvement in hepatic glucose metabolism, but not necessarily alterations in dynamic glucose disposal. Mice engaging in wheel running or forced treadmill running do not require muscle glycogen, but can maintain energy needs through gluconeogenesis and glycogenolysis in the liver (37). After exhaustive exercise, muscle glycogen levels are replenished preferentially upon refeeding after exercise (9). However, in our exercise model, VWR likely 
did not promote exhaustion. Low-, moderate-, and high-dose insulin tolerance testing may provide unique insight into tissuespecific adaptations to VWR.

Importantly, liver and serum TAG levels were markedly reduced in exercised mice while muscle levels were not significantly different (Fig. 4), findings that have previously been reported in 4-wk exercise-trained HFD-fed mice (20). During acute exercise, C57BL/6J mice increase hepatic glucose production to maintain glycemia via increased glycogenolysis and gluconeogenesis (17). Considering the similar trends in glucose tracer $\left(6,6-{ }^{2}[\mathrm{H}]\right.$ glucose $)$ disposal and the differential pattern of endogenous glucose levels during the OGTT between the sedentary and exercised mice, these data suggest that adaptations in the liver may explain the improvement in glycemia that occur with VWR.

In our studies, muscle insulin signaling was significantly increased in both sedentary and exercised mice, but not the increase in insulin-mediated phosphorylation of Akt was not greater in the HFD Ex mice. This observation is not surprising in a consideration of evidence that phosphorylation of Akt is not necessary for exercise-induced improvements in insulin sensitivity (8). However, we did detect a significant increase in hepatic insulin-mediated Akt phosphorylation in HFD Ex mice compared with HFD Sed mice. Our in vivo SI-OGTT also supports an improved hepatic response to glucose and insulin for HFD Ex mice. Additionally, hepatic FOXO1 mRNA levels were elevated in the exercised group, suggesting that at least some aspect of gluconeogenesis was altered due to wheel running.

There were discrepancies between pAMPK levels in skeletal muscle and liver protein levels (Fig. 5). Exercise increased pAMPK levels significantly, but not in the liver (HFD Ex vs. HFD Sed). This observation is somewhat expected in the consideration of data that show that forced treadmill exercise in the fasted state was required to increase muscle and hepatic AMP levels (2). However, this result could also be considered somewhat unexpected given the near significant reduction in hepatic glycogen content measured in exercised mice (Fig. 4D). Overall, these observations may reflect the adapted state to lower hepatic glycogen content rather than acute activation of AMPK via increased AMP accumulation. The increase in skeletal muscle phosphorylation of AMPK would suggest smaller perturbation in the energetic state can sufficiently activate this pathway.

PDK4 is a negative regulator of the PDH complex and reduces pyruvate flux into the mitochondria to favor fatty acid oxidation (4). Skeletal muscle PDK4 protein levels trended to be increased in HFD Ex mice, which likely corresponds to a greater shift toward fat oxidation. Interestingly, while protein content in the liver for PDK4 was not different between sedentary and exercised groups, PDK4 mRNA levels were significantly reduced in exercised mice (Fig. 6). These data demonstrate the known differential responses to exercise between skeletal muscle and the liver $(15,19,24,38,40)$. Increased PKD4 in the skeletal muscle likely promotes the glycogen synthetic response by preserving gluconeogenic substrates derived from pyruvate (15). Whereas reduced PDK4 mRNA levels in the liver are associated with the promotion of glucose oxidation (38). Similarly, genetic inactivation of liver PKD4 markedly improves hepatic insulin resistance and reduces hepatic glucose production, suggesting that control of hepatic PKD4 expression plays a role in mediating the metabolic effects of exercise $(35,42)$.
After oral glucose ingestion, glucose disposal is shared primarily between the skeletal muscle and the liver ( 30\% for both tissues) $(18,22,36)$. Oral glucose tolerance testing provides a physiological route for glucose to promote insulin secretion; however, factors such as EGP and glucose disposal remain unknown. The improved efficiency of liver glucose uptake and suppression of glucose output is not often considered in the adaptations to exercise training. The startling worldwide upsurge in fatty liver diseases emphasizes the importance of exploring hepatic adaptations to exercise training. To our knowledge, this is the first report to demonstrate postprandial glucose dynamics using stable isotope tracers in exercising high fat-fed mice influenced by reduced fasting glucose and lower endogenous glucose excursion in response to VWR. Overall, these observations expand our knowledge of the physiological adaptations that occur in this well-studied mouse model of metabolic disease.

\section{ACKNOWLEDGMENTS}

We thank Tamra Mendoza for assisting in animal experiments.

\section{GRANTS}

This work was also supported by the National Center for Complementary and Integrative Health (NCCIH) and the Office of Dietary Supplements of the National Institutes of Health under (Award Number P50AT002776, U54 GM104940, P30GM118430, P30DK072476, and S10OD023703). T. D. Allerton is supported by NCCIH T32 AT004094 and L30 DK122484.

\section{DISCLOSURES}

No conflicts of interest, financial or otherwise, are declared by the authors.

\section{AUTHOR CONTRIBUTIONS}

T.D.A. conceived and designed research; T.D.A. and H.H. performed experiments; T.D.A. and G.K. analyzed data; T.D.A. and J.S. interpreted results of experiments; T.D.A. prepared figures; T.D.A. drafted manuscript; T.D.A., G.K., and J.S. edited and revised manuscript; T.D.A., G.K., H.H., and J.S. approved final version of manuscript.

\section{REFERENCES}

1. Ali MK, Bullard KM, Saydah S, Imperatore G, Gregg EW. Cardiovascular and renal burdens of prediabetes in the USA: analysis of data from serial cross-sectional surveys, 1988-2014. Lancet Diabetes Endocrinol 6: 392-403, 2018. doi:10.1016/S2213-8587(18)30027-5.

2. Camacho RC, Donahue EP, James FD, Berglund ED, Wasserman DH. Energy state of the liver during short-term and exhaustive exercise in C57BL/6J mice. Am J Physiol Endocrinol Metab 290: E405-E408, 2006. doi:10.1152/ajpendo.00385.2005.

3. Carter LG, Ngo Tenlep SY, Woollett LA, Pearson KJ. Exercise improves glucose disposal and insulin signaling in pregnant mice fed a high fat diet. $J$ Diabetes Metab 6: 634, 2015. doi:10.4172/2155-6156.1000634.

4. Connaughton S, Chowdhury F, Attia RR, Song S, Zhang Y, Elam MB, Cook GA, Park EA. Regulation of pyruvate dehydrogenase kinase isoform 4 (PDK4) gene expression by glucocorticoids and insulin. Mol Cell Endocrinol 315: 159-167, 2010. doi:10.1016/j.mce.2009.08.011.

5. Dalbram E, Basse AL, Zierath JR, Treebak JT. Voluntary wheel running in the late dark phase ameliorates diet-induced obesity in mice without altering insulin action. J Appl Physiol (1985) 126: 993-1005, 2019. doi:10.1152/japplphysiol.00737.2018.

6. DeFronzo RA. Pathogenesis of type 2 diabetes mellitus. Med Clin North Am 88: 787-835, 2004. doi:10.1016/j.mcna.2004.04.013.

7. Efendić S, Wajngot A, Vranić M. Increased activity of the glucose cycle in the liver: early characteristic of type 2 diabetes. Proc Natl Acad Sci USA 82: 2965-2969, 1985. doi:10.1073/pnas.82.9.2965.

8. Frøsig C, Richter EA. Improved insulin sensitivity after exercise: focus on insulin signaling. Obesity (Silver Spring) 17, Suppl 3: S15-S20, 2009. doi:10.1038/oby.2009.383. 
9. Garetto LP, Richter EA, Goodman MN, Ruderman NB. Enhanced muscle glucose metabolism after exercise in the rat: the two phases. Am J Physiol 246: E471-E475, 1984. doi:10.1152/ajpendo.1984.246.6.E471.

10. Gomes FR, Rezende EL, Malisch JL, Lee SK, Rivas DA, Kelly SA, Lytle C, Yaspelkis BB, Garland T. Glycogen storage and muscle glucose transporters (GLUT-4) of mice selectively bred for high voluntary wheel running. J Exp Biol 212: 238-248, 2009. doi:10.1242/jeb.025296.

11. Han DH, Hansen PA, Chen MM, Holloszy JO. DHEA treatment reduces fat accumulation and protects against insulin resistance in male rats. J Gerontol A Biol Sci Med Sci 53A: B19-B24, 1998. doi:10.1093/ gerona/53A.1.B19.

12. Han Y, Oshida Y, Li L, Koshinaka K, Fuku N, Yamanouchi K, Sato Y. Effect of voluntary wheel-running on insulin sensitivity and responsiveness in high-fat-fed rats. Endocr J 48: 551-555, 2001. doi:10.1507/ endocrj.48.551

13. Hansen PA, Nolte LA, Chen MM, Holloszy JO. Increased GLUT-4 translocation mediates enhanced insulin sensitivity of muscle glucose transport after exercise. J Appl Physiol (1985) 85: 1218-1222, 1998. doi:10.1152/jappl.1998.85.4.1218.

14. Hawley JA, Lessard SJ. Exercise training-induced improvements in insulin action. Acta Physiol (Oxf) 192: 127-135, 2008. doi:10.1111/j. 1748-1716.2007.01783.x.

15. Herbst EAF, MacPherson REK, LeBlanc PJ, Roy BD, Jeoung NH, Harris RA, Peters SJ. Pyruvate dehydrogenase kinase-4 contributes to the recirculation of gluconeogenic precursors during postexercise glycogen recovery. Am J Physiol Regul Integr Comp Physiol 306: R102-R107, 2014. doi:10.1152/ajpregu.00150.2013.

16. Houmard JA, Tanner CJ, Slentz CA, Duscha BD, McCartney JS, Kraus WE. Effect of the volume and intensity of exercise training on insulin sensitivity. J Appl Physiol (1985) 96: 101-106, 2004. doi:10.1152/ japplphysiol.00707.2003.

17. Hughey CC, James FD, Bracy DP, Donahue EP, Young JD, Viollet B, Foretz M, Wasserman DH. Loss of hepatic AMP-activated protein kinase impedes the rate of glycogenolysis but not gluconeogenic fluxes in exercising mice. J Biol Chem 292: 20125-20140, 2017. doi:10.1074/jbc. M117.811547.

18. Jackson RA, Roshania RD, Hawa MI, Sim BM, DiSilvio L. Impact of glucose ingestion on hepatic and peripheral glucose metabolism in man: an analysis based on simultaneous use of the forearm and double isotope techniques. J Clin Endocrinol Metab 63: 541-549, 1986. doi:10.1210/ jcem-63-3-541.

19. Jeoung NH, Harris RA. Pyruvate dehydrogenase kinase-4 deficiency lowers blood glucose and improves glucose tolerance in diet-induced obese mice. Am J Physiol Endocrinol Metab 295: E46-E54, 2008. doi:10.1152/ajpendo.00536.2007.

20. Jordy AB, Kraakman MJ, Gardner T, Estevez E, Kammoun HL, Weir JM, Kiens B, Meikle PJ, Febbraio MA, Henstridge DC. Analysis of the liver lipidome reveals insights into the protective effect of exercise on high-fat diet-induced hepatosteatosis in mice. Am J Physiol Endocrinol Metab 308: E778-E791, 2015. doi:10.1152/ajpendo.00547.2014.

21. Jung AP, Luthin DR. Wheel access does not attenuate weight gain in mice fed high-fat or high-CHO diets. Med Sci Sports Exerc 42: 355-360, 2010. doi:10.1249/MSS.0b013e3181a6d88f.

22. Kelley D, Mitrakou A, Marsh H, Schwenk F, Benn J, Sonnenberg G, Arcangeli M, Aoki T, Sorensen J, Berger M. Skeletal muscle glycolysis, oxidation, and storage of an oral glucose load. J Clin Invest 81: 1563 1571, 1988. doi:10.1172/JCI113489.

23. Kern M, Tapscott EB, Downes DL, Frisell WR, Dohm GL. Insulin resistance induced by high-fat feeding is only partially reversed by exercise training. Pflügers Arch 417: 79-83, 1990. doi:10.1007/BF00370772.

24. Knudsen JG, Biensø RS, Hassing HA, Jakobsen AH, Pilegaard H. Exercise-induced regulation of key factors in substrate choice and gluconeogenesis in mouse liver. Mol Cell Biochem 403: 209-217, 2015. doi:10.1007/s11010-015-2351-0.

25. Kowalski GM, Bruce CR. The regulation of glucose metabolism: implications and considerations for the assessment of glucose homeostasis in rodents. Am J Physiol Endocrinol Metab 307: E859-E871, 2014. doi:10. 1152/ajpendo.00165.2014.

27. Kowalski GM, De Souza DP, Burch ML, Hamley S, Kloehn J, Selathurai A, Tull D, O'Callaghan S, McConville MJ, Bruce CR. Application of dynamic metabolomics to examine in vivo skeletal muscle glucose metabolism in the chronically high-fat fed mouse. Biochem Biophys Res Commun 462: 27-32, 2015. doi:10.1016/j.bbrc.2015.04.096.
28. Kowalski GM, Hamley S, Selathurai A, Kloehn J, De Souza DP, O'Callaghan S, Nijagal B, Tull DL, McConville MJ, Bruce CR. Reversing diet-induced metabolic dysregulation by diet switching leads to altered hepatic de novo lipogenesis and glycerolipid synthesis. Sci Rep 6: 27541, 2016. doi:10.1038/srep27541.

29. Kowalski GM, Kraakman MJ, Mason SA, Murphy AJ, Bruce CR. Resolution of glucose intolerance in long-term high-fat, high-sucrose-fed mice. J Endocrinol 233: 269-279, 2017. doi:10.1530/JOE-17-0004.

30. Kraegen EW, Storlien LH, Jenkins AB, James DE. Chronic exercise compensates for insulin resistance induced by a high-fat diet in rats. Am J Physiol 256: E242-E249, 1989. doi:10.1152/ajpendo.1989.256.2.E242.

31. LaBarge SA, Migdal CW, Buckner EH, Okuno H, Gertsman I, Stocks B, Barshop BA, Nalbandian SR, Philp A, McCurdy CE, Schenk S. p300 is not required for metabolic adaptation to endurance exercise training. FASEB J 30: 1623-1633, 2016. doi:10.1096/fj.15-281741.

32. Manzanares G, Brito-da-Silva G, Gandra PG. Voluntary wheel running: patterns and physiological effects in mice. Braz J Med Biol Res 52: e7830, 2019. doi:10.1590/1414-431×20187830.

33. Novak CM, Burghardt PR, Levine JA. The use of a running wheel to measure activity in rodents: relationship to energy balance, general activity, and reward. Neurosci Biobehav Rev 36: 1001-1014, 2012. doi:10. 1016/j.neubiorev.2011.12.012

34. O'Keefe JH, Bell DSH. Postprandial hyperglycemia/hyperlipidemia (postprandial dysmetabolism) is a cardiovascular risk factor. Am J Cardiol 100: 899-904, 2007. doi:10.1016/j.amjcard.2007.03.107.

35. Park BY, Jeon JH, Go Y, Ham HJ, Kim JE, Yoo EK, Kwon WH, Jeoung NH, Jeon YH, Koo SH, Kim BG, He L, Park KG, Harris RA, Lee IK. PDK4 deficiency suppresses hepatic glucagon signaling by decreasing cAMP levels. Diabetes 67: 2054-2068, 2018. doi:10.2337/db17-1529.

36. Patterson B. Isotope tracers in metabolic research. Principles and Practice of Kinetic Analysis (2nd ed.), edited by Wolfe RR and Chinkes DL. New York: Wiley-Liss, 2005. doi:10.1016/j.jasms.2005.02.007.

37. Pederson BA, Schroeder JM, Parker GE, Smith MW, DePaoli-Roach AA, Roach PJ. Glucose metabolism in mice lacking muscle glycogen synthase. Diabetes 54: 3466-3473, 2005. doi:10.2337/diabetes.54.12.3466.

38. Pilegaard H, Neufer PD. Transcriptional regulation of pyruvate dehydrogenase kinase 4 in skeletal muscle during and after exercise. Proc Nutr Soc 63: 221-226, 2004. doi:10.1079/PNS2004345.

39. Richter EA, Garetto LP, Goodman MN, Ruderman NB. Enhanced muscle glucose metabolism after exercise: modulation by local factors. Am J Physiol Endocinol Metab 246: E476-E482, 1984. doi:10.1152/ajpendo. 1984.246.6.E476.

40. Rinnankoski-Tuikka R, Silvennoinen M, Torvinen S, Hulmi JJ, Lehti M, Kivelä R, Reunanen H, Kainulainen H. Effects of high-fat diet and physical activity on pyruvate dehydrogenase kinase- 4 in mouse skeletal muscle. Nutr Metab (Lond) 9: 53, 2012. doi:10.1186/1743-7075-9-53.

41. Stanford KI, Takahashi H, So K, Alves-Wagner AB, Prince NB, Lehnig AC, Getchell KM, Lee M-Y, Hirshman MF, Goodyear LJ. Maternal exercise improves glucose tolerance in female offspring. Diabetes 66: 2124-2136, 2017. doi:10.2337/db17-0098.

42. Tao R, Xiong X, Harris RA, White MF, Dong XC. Genetic inactivation of pyruvate dehydrogenase kinases improves hepatic insulin resistance induced diabetes. PLoS One 8: e71997, 2013.

43. Vaitheesvaran B, Chueh FY, Xu J, Trujillo C, Saad MF, Lee WNP, McGuinness OP, Kurland IJ. Advantages of dynamic "closed loop" stable isotope flux phenotyping over static "open loop" clamps in detecting silent genetic and dietary phenotypes. Metabolomics 6: 180-190, 2010. doi:10.1007/s11306-009-0190-2.

44. Vaitheesvaran B, LeRoith D, Kurland IJ. MKR mice have increased dynamic glucose disposal despite metabolic inflexibility, and hepatic and peripheral insulin insensitivity. Diabetologia 53: 2224-2232, 2010. doi: 10.1007/s00125-010-1827-4.

45. Way KL, Hackett DA, Baker MK, Johnson NA. The effect of regular exercise on insulin sensitivity in type 2 diabetes mellitus: A systematic review and meta-analysis. Diabetes Metab J 40: 253-271, 2016. doi:10. 4093/dmj.2016.40.4.253.

46. Winzell MS, Ahrén B. The high-fat diet-fed mouse: a model for studying mechanisms and treatment of impaired glucose tolerance and type 2 diabetes. Diabetes 53, Suppl 3: S215-S219, 2004. doi:10.2337/diabetes. 53.suppl_3.S215.

47. Yang Y, Smith DL Jr, Keating KD, Allison DB, Nagy TR. Variations in body weight, food intake and body composition after long-term high-fat diet feeding in C57BL/6J mice. Obesity (Silver Spring) 22: 2147-2155, 2014. doi:10.1002/oby.20811. 